\title{
WOOD CHILE PEPPERS STALKS-PLASTIC COMPOSITE PRODUCTION
}

\author{
Delia J. Valles-Rosales ${ }^{1, \star}$, Luis C. Méndez-González ${ }^{2}$, Luis A. Rodríguez-Picon ${ }^{3}$, Arturo del \\ Valle-Carrasco ${ }^{4}$, Haytham A. Alodan
}

\begin{abstract}
Nowadays, most common wood fibers used to produce wood plastic composites are from Oak and pine trees, rice hull, recycled paper, pallets and post-industrial oak fiber, furniture waste, or cedar wood chips. This paper is focused on a new wood plastic composites based on pre-dried New Mexico red chile stems and leafs with high-density polyethylene. The specimens were manufactured following ASTM 638-9 standard using injection molding. A series of experiments were designed to investigate how wood fiber length, geometry, and water absorption affects the microcellular structure of the new sustainable material. The effects of proportions and particle size on the strength of the resulting blend were analyzed. It was found that larger particle sizes of wood fiber showed higher mechanical properties. The blending of additives in the new sustainable material has shown to increase proper fiber dispersion improving the strength of the material.
\end{abstract}

Keywords: Chile pepper stems, Pinus resinosa, tensile properties, water absorption, wood plastic composite.

\section{INTRODUCTION}

Wood Plastic Composite (WPC) is a very promising and sustainable green material to achieve durability without using toxic chemicals. The term WPC refers to any composites that contain plant fiber and thermosets or thermoplastics. In comparison to other fibrous materials, plant fibers are in general suitable to reinforce plastics due to relative high strength and stiffness, low cost, low density, low $\mathrm{CO}_{2}$ emission, biodegradability and annual renewability (Ashori 2008).

\footnotetext{
${ }^{1}$ Associate Professor, Department of Industrial Engineering, MSC 4230/ECIII, Rm 288. New Mexico State University. Las Cruces, New Mexico. USA.

${ }^{2}$ Research Professor, Department of Industrial Engineering and Manufacturing, Autonomous University of Ciudad Juárez, Cd. Juárez, Chihuahua, Mexico.luis.mendez@uacj.mx.

${ }^{3}$ Research Professor, Department of Industrial Engineering and Manufacturing, Autonomous University of Ciudad Juárez, Cd. Juárez, Chihuahua, México.luis.picon@uacj.mx.

${ }^{4}$ College Instructor, Graduate School, New Mexico State University, Las Cruces, New Mexico State University. Las Cruces, New Mexico. USA. arturodelvalle@me.com.

${ }^{5}$ Manager of the National Center for Industrial Development, Assistant Research Professor of Industrial Engineering, King Abdulaziz City for Science and Technology (KACST), Riyadh, Saudi Arabia. halodan@kacst.edu.sa

•Corresponding author: dvalles@nmsu.edu

Received: 10.12.2014 Accepted: 28.11.2015
} 
WPC materials are based on oaks, recycled paper, and other agro waste. Today researchers are investigating various biomass resources as fibers to be coupled with polymers for fulfilling the need of new applications. For example Pulido-González et al. (2014) evaluated the mechanical properties to produce WPC based on Polypropylene (PP) as polymer matrix and discarded agave fiber (tequila Weber). Fabiyi and McDonald (2010), showed the effect of wood species on mechanical, thermal, and accelerated weathering behavior of WPC made of High Density Polyethylene polymer. Bouafif et al. (2009), found that mechanical properties vary significantly with fiber origin. They investigated fiber variability, size, and contents on water up take, tensile strength, and flexural strength. Moreover, Wang et al. (2008) considered the impact of the moisture content, bamboo particles and the proportion between Bamboo and Polyvinylchloride. Also, Ozdemir et al. (2014) explore the dimension stability of WPC made from PP and pine wood flour with and without coupling agents via injection molding techniques. Yoo \& Oh (2011) investigated the possibility of using chile pepper stalks as a raw material mixed with Urea-formaldehyde $50 \%-50 \%$ to produce particleboards that exceed the minimum strength requirements of the Korean standards of Particleboards products. The studies mentioned above, employed local materials in their research; in this study the New Mexico's red chile pepper plants, leafs, and stems represent one opportunity for investigation and a potential source of plant-based fiber reinforcing additives.

For this study, a WPC with chile leafs and stems is proposed as a new composite material in order to investigate the behavior of polyethylene composites mixed with chile waste. In addition, this article examines the repercussions that the process and the fiber size have on WPC production, on their mechanical properties, on their water absorption and their morphological characteristics. Specimens were manufactured following ASTM 638-9 standard using injection molding. Particle sizes of New Mexico red chile pepper are utilized in different ratios of length to diameter. An ANOVA was used to analyze the material combinations' significance on the properties of each sample obtained.

\section{MATERIALS AND METHODS}

\section{Materials}

In this section, the materials employed to produce the WPC are described for the proposed research.

\section{Wood}

Virgin Pine (VP), recycled urea formaldehyde(UF) bonded PB, and recycled CCA-treated red pine wood with $6 \mathrm{~kg} / \mathrm{m}^{3}$ CCA total oxides retention were used to produce the WPC. Untreated kiln dried red pine boards with an average moisture content of $12 \%$ and CCA-treated red pine (Pinus resinosa Ait) poles removed after 21 years in service (Wechsler \& Hiziroglu 2007).

\section{Chile stems}

Chile pepper is a major crop in New Mexico, West Texas and East Arizona. 40\% of the total chile crops in the US are produced in New Mexico. Wood fibers represent $40 \%$ to $60 \%$ of an average size chile plant, which represent approximately $51 \%$ of Chile wood fibers after drying. Chile stems wastes were used as a plant-based reinforcing material. The stems were collected from Biad Chile dryer in Las Cruces, New Mexico. The window timing of the harvesting season of chile starts late of August and end early January. Table 1 shows the data measured for constituents of the chile wastes stems recollected for this experiment.

Table 1. Constituents (\%) of chile pepper stems.

\begin{tabular}{ccccccc}
\hline Lignin & $\begin{array}{c}\text { Cellulose } \\
\text { (Glucose) }\end{array}$ & $\begin{array}{c}\text { Hemicellulose } \\
\text { (xylose) }\end{array}$ & Holocellulose & Ash & $\begin{array}{c}\text { Extractives (pectin } \\
\text { and wax) }\end{array}$ & $\begin{array}{c}\text { Water } \\
\text { Content }\end{array}$ \\
\hline 27,8 & 45,1 & 26,1 & 78,7 & 5,8 & 2,4 & 9,2 \\
\hline
\end{tabular}




\section{Additive and Fire Retardant}

Used Additives were Maleic Anhydride Grafted Polypropylene (MAPP) supplied by Chemtura Co.(POLYBOND ${ }^{@} 3200$, density $0,91 \mathrm{~g} / \mathrm{cm}^{3}$, melt flow index $115 \mathrm{~g} / 10 \mathrm{~min}$, melting point $157^{\circ} \mathrm{C}$ ) used as interfacial enhancement agent. Also, LOWILTE ${ }^{@} 19$, (flash point $278^{\circ} \mathrm{C}$, Ignition temperature $330^{\circ} \mathrm{C}$, melting point range $115-150^{\circ} \mathrm{C}$, thermal decomposition $350^{\circ} \mathrm{C}$ ) employed as a light stabilizer supplied by Chemtura Co. Moreover, Non-halogenated flame retardant JJAZZ ${ }^{\circledR}$ (JJAZZ SP1; melting point $>250^{\circ} \mathrm{C}$, specific gravity $1,3-1,35$ ) supplied by JJI Technologies used to stabilize the material during processing and reduce the fibers heat degradation as possible.

\section{Methods}

This section is divided in two parts. In the first part, the Design of Experiments (DOE) proposed to produce the specimens is explained. The second part describes the fabrication process employed to obtain the specimens of WPC.

\section{Proposed DOE}

A $3^{6} \mathrm{DOE}$ was performed with different factors categorized in two groups: materials and process parameters. Processing parameters include barrel temperature, nozzle temperature, injection time, and mold temperature controlled at $49^{\circ} \mathrm{C}$, Material humidity and weight were controlled at $8 \%$ and 244,9 grams respectively. Chile leafs and stem wood were dried in an oven 24 hours at $70^{\circ} \mathrm{C}$ and grinded to various mesh sizes. Recycled Polyethylene (rPE) was used on levels of 25, 50, 75, and 100\%, these different levels were combined with chile pepper dust at levels of $75,50,25$, and $0 \%$ respectively to complete our composite formulation. These combinations were replicated using Chile pepper dust with different mesh sizes of 30, 80, and 120 mesh. Ingredients were blended and humidity levels were brought down to a $9 \%$ level using a desiccator for 4 days. In Table 2, a summary of the DOE proposed for the fabrication of the specimens is presented.

Table 2. DOE proposed.

\begin{tabular}{|c|cc|}
\hline Category & Factor & Value \\
\hline \multirow{3}{*}{ Material } & Composition: \% of Wood & $25 \%, 50 \%, 75 \%$ \\
\cline { 2 - 3 } & \% of Recycled polyethylene (rPE) & $25 \%, 50 \%, 75 \%$ \\
\cline { 2 - 3 } & Grain size of Wood & $30,80,120 \mathrm{microns}$ \\
\hline \multirow{3}{*}{ Processing } & Barrel and nozzle temperature & $149^{\circ} \mathrm{C}, 177{ }^{\circ} \mathrm{C}$ \\
\cline { 2 - 3 } & Injection Time & $20 \mathrm{sec}, 40 \mathrm{sec}$ \\
\cline { 2 - 3 } & Melting residence time & $2,5 \mathrm{~min} ; 5 \mathrm{~min}$ \\
\hline
\end{tabular}

\section{Sampling preparation}

Materials were preheated using a heating device for better mixing of the materials; in Figure 1, the material without heating (Figure 1a) and with heating process (Figure 1b) is showed. Then, using an experimental plunger injection molding machine (IM plunger type Industrial Plastic Cender Co., Model T9013-P) the composite combinations were produced according to ASTM 638-09 standard. 


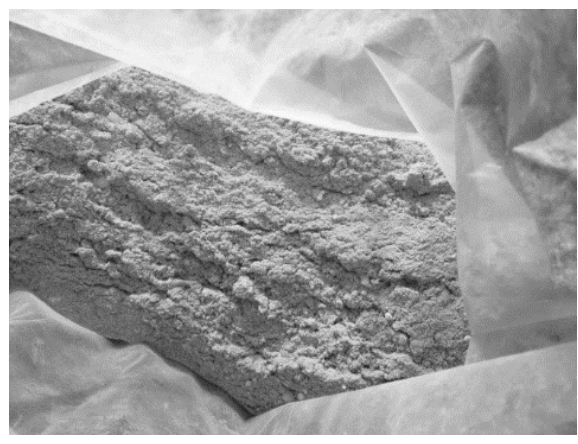

(a)

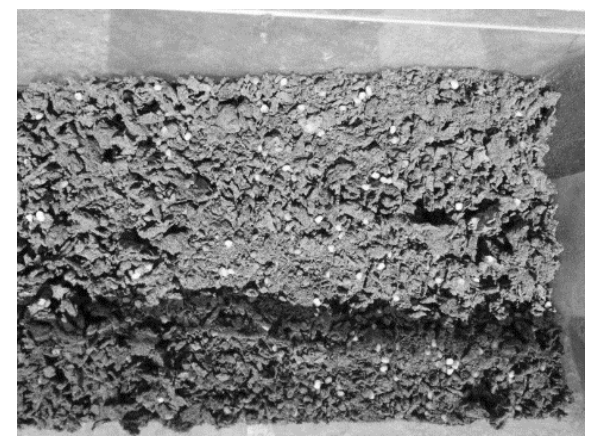

(b)

Figure 1. Material traded by heating process. (a) Grinding Machine. (b) Sieving machine.

Particles were collected in two different groups according to their size. After that, these two groups were put in an oven for dehumidifying; the resulting humidity was $4 \%$, which is a percentage followed by previous research. Then these particles were put in a vacuum chamber to maintain the humidity for later use.

The Chile stem waste particles were mixed together in the following proportions $300 \mathrm{~g}$ of PP, $125 \mathrm{~g}$ of MAPP coupling agent, UV stabilizer (3,5\% of concentration), and a fire retardant agent according to the design of experiment in Table 2 in 300 grams total weight for each combination. Chile stem waste particles were put in a furnace for $24 \mathrm{~h}$ under $80^{\circ} \mathrm{C}$ and reduced the humidity from $10 \%$ to $4 \%$. After that, mixtures were heated under manual continuous heating for 15 minutes at $121,1^{\circ} \mathrm{C}$ before pelletizing. Then the combinations were produced as specimens (according to ASTM D63803) using experimental plunger injection molding machine (IM plunger type Industrial Plastic Cender Co., Model T9013-P). Conditions of processing were as following: barrel temperature $160{ }^{\circ} \mathrm{C}$, nozzle temperature varied between $176,6-287,7^{\circ} \mathrm{C}$ according to the material constituents, injection pressure 1250 bar, injection time $30 \mathrm{sec}$. On Figure 2, the cavity employed to produce the samples is showed; Figure 3 shows the process employed to generate the WPC samples.

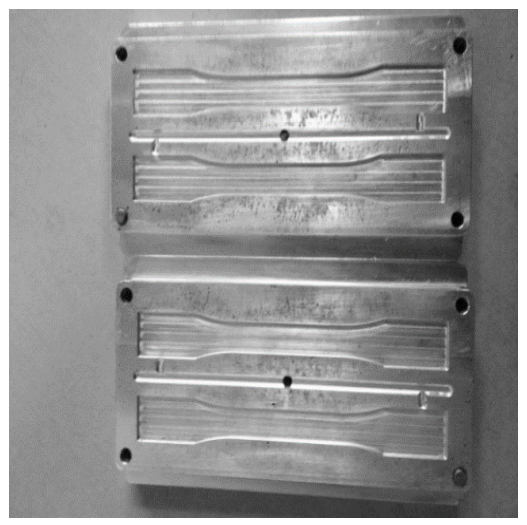

Figure 2. Cavity mold used. 


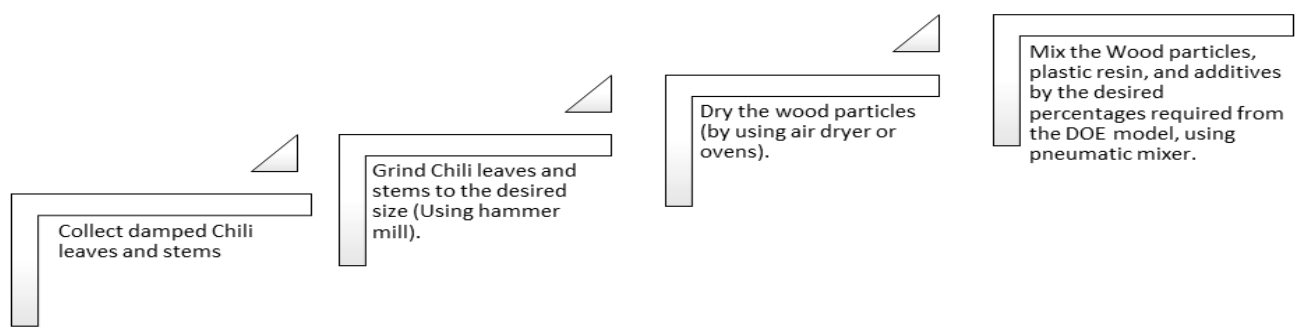

Figure 3. Process of preparing material for WPC proposed.

\section{Sampling testing}

The sampless obtained in the experiment were analyzed in their mechanical, physical and morphological properties. All tests conducted were following established procedures according to ASTM standards.

Mechanical properties were tested by a tension test, flexural bending test, and Charpy impact resistance test ASTM D638-03 and ASTM D6110-06 respectively were conducted to analyze the effects of material compositions and grains sizes on yield stress, ultimate tensile stress and the strains corresponding to these stresses. Similarly, impact resistance is studied. In Figure 4, the tension and bending machine test instrument is showed.

The physical properties were studied via water absorption according to ASTM D570-98 to investigate the role of the material contents and the particle size.

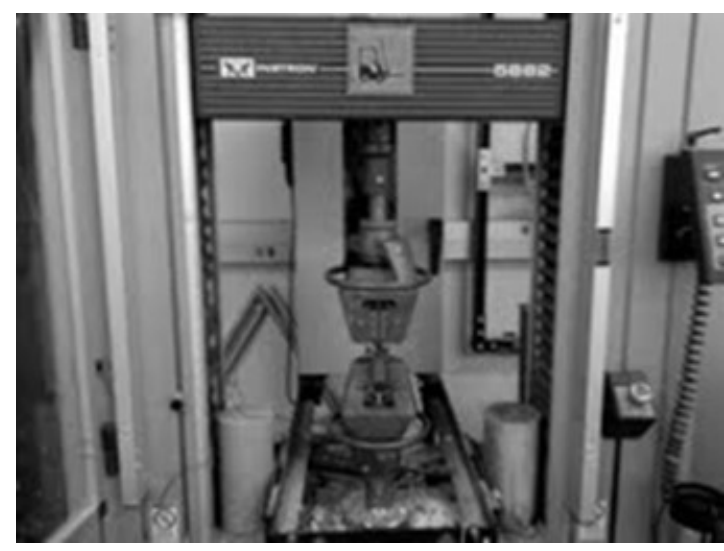

Figure 4. Tension test machine.

Morphology of the material was investigated using SEM (Scanning electron microscope, S-3400N Type II, Hitachi High-Technologies Corp., of four magnifications, 20X, 100X, 200X, and 500X of each combination, also TCS SP5 II broadband confocal microscope was used. Images of the tension test fracture surface samples were the subject of study.

In all studies, fresh samples were tested for their mechanical and physical properties. After that, environmental experiments were done on different samples with the same materials using actual weathering. Samples of each combination were put outside under actual weathering for 
four months; starting from $25 / 5 / 2013$ to $1 / 11 / 2013$. After that, these samples were tested using tension test and bending tests to investigate the effect of weather on the mechanical properties with presence of UV stabilizer agent. Mechanical properties before and after weathering were compared to evaluate the significance of change and investigate the effects of weather.

\section{RESULTS}

Based on the DOE proposed in section 2, WPC samples were produced and the samples were analyzed via ANOVA. The results obtained demonstrate the best way to produce WPC with red chile stems. Figure 5 shows a sample of the specimen produced.

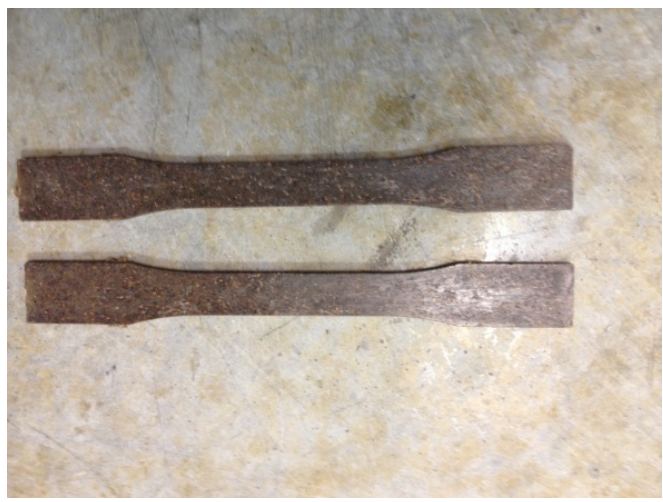

Figure 5. WPC samples obtained with proposed DOE.

\section{Mechanical properties results}

Based on the procedure established previously, mechanical tests were made for the specimens produced. A summary of the results obtained for the mechanical tests can be seen in Table 3. Also, in Figure 6 , can be seen the profile generated by the specimens produced.

Table 3. Summary of results obtained of mechanical test.

\begin{tabular}{|c|c|c|c|c|c|c|c|c|}
\hline & $\begin{array}{c}100 \\
\% \mathrm{rPE}\end{array}$ & $\begin{array}{l}75 \% \mathrm{rPE}, \\
25 \% \mathrm{~W}\end{array}$ & $\begin{array}{c}75 \% \mathrm{rPE}, \\
25 \% \mathrm{~W}\end{array}$ & $\begin{array}{c}75 \% \mathrm{rPE}, \\
25 \% \mathrm{~W}\end{array}$ & $\begin{array}{c}\mathbf{5 0} \% \mathrm{rPE}, \\
\mathbf{5 0} \% \mathrm{~W}\end{array}$ & $\begin{array}{c}\mathbf{5 0} \% \mathrm{rPE} \\
\mathbf{5 0} \% \mathrm{~W}\end{array}$ & 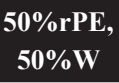 & $\begin{array}{c}25 \% \mathrm{rPE}, \\
75 \% \mathrm{~W}\end{array}$ \\
\hline & & 30mesh & $80 m e s h$ & 120mesh & 30mesh & 80mesh & 120 mesh & 30mesh \\
\hline $\begin{array}{c}\text { Average } \\
\text { Ultimate } \\
\text { Tensile Stress } \\
\text { (UTS) (MPa) }\end{array}$ & 20,3 & 18,6 & 17,2 & 16,3 & 17,9 & 17,8 & 15,8 & 11,2 \\
\hline $\begin{array}{l}\text { Average Yield } \\
\text { Stress (MPa) }\end{array}$ & 9,7 & 9,9 & 9,1 & 8,7 & 8,9 & 8,9 & 9,0 & 8,7 \\
\hline
\end{tabular}

The tensile properties found vary significantly according to the material composition. Moreover, tensile stress is not significantly affected by particle size; however, the tensile strains do vary significantly by the particles' sizes. The ultimate tensile stress and the braking stress additionally have the same trend. The variation is between 11,2 MPa to $18,6 \mathrm{MPa}$ for average UTS and 8,7 $\mathrm{MPa}$ to 25,8 $\mathrm{MPa}$ for breaking stress. However, there is no evidence that the averages are affected by the particle sizes. 


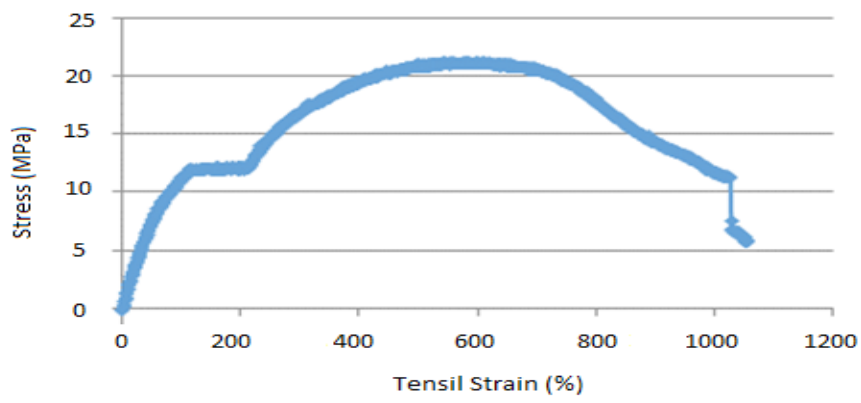

(a)

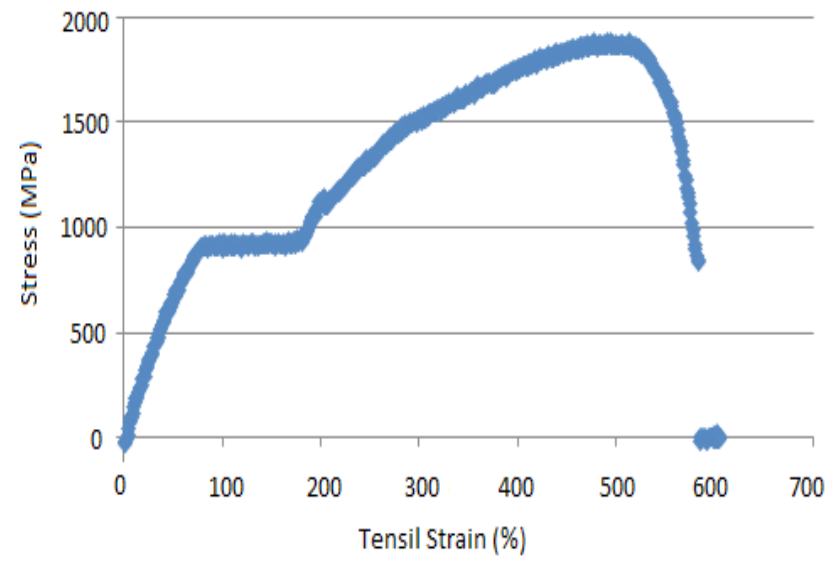

(b)

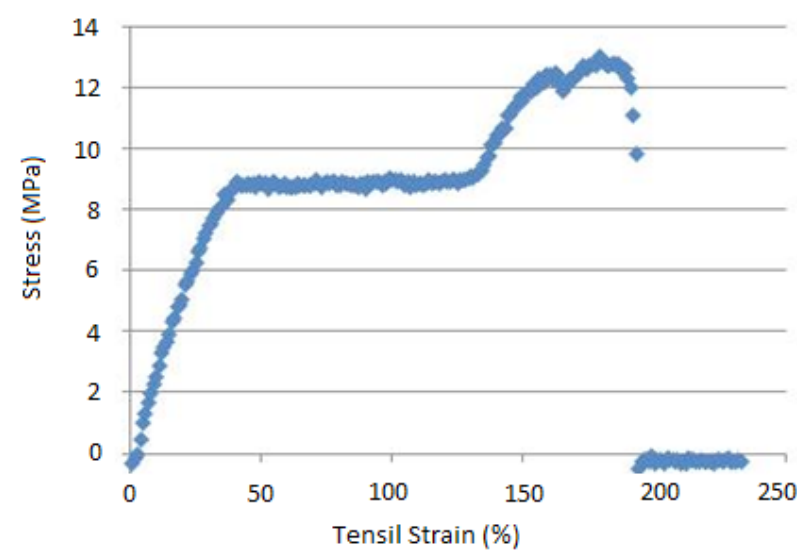

(c)

Figure 6. Mechanical profiles generated by specimens under DOE levels. (a) Profile generated by Stress (Mpa), specimens under 75\%rPE, 25\% Wood, 120 mesh. (b) Profile generated by Stress (Mpa), specimens under 50\%rPE, 50\% Wood, 80 mesh. (c) Profile generated by Stress (Mpa), specimens under 25\%rPE, $75 \%$ Wood, 30 mesh. 
To prove this statement, a two-way ANOVA was performed by taking the UTS vs mesh combination and yield stress. The results of the ANOVA is showed in Table 4 and Figure 7 for UTS vs mesh and Table 5 and Figure 8 for yield stress. In addition, since the chile, stems used in this research are particles and not fibers with aspect ratio, larger grain size provide higher internal stresses within the material, which lead to lower mechanical properties. Moreover, increasing the quantity chile stem particles reduced the ultimate tensile stress and the breaking stress.

Table 4. Results Obtained from ANOVA performed UTS versus Mesh size Combination.

\begin{tabular}{|llllll|}
\hline \multicolumn{7}{|l|}{ Analysis of Variance } \\
Source DF & Adj SS & Adj MS & F-Value & P-Value \\
Comb & 1 & 0,04541 & 0,04541 & 0,18 & 0,711 \\
Mesh & 2 & 5,15575 & 2,57787 & 10,33 & 0,088 \\
Error & 2 & 0,49930 & 0,24965 & & \\
Total & 5 & 5,70046 & & \\
\end{tabular}

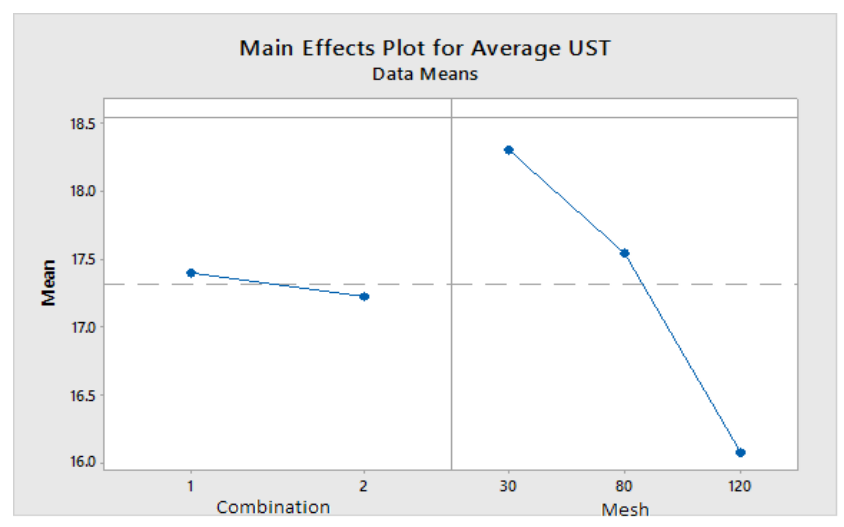

Figure 7. Main effects plot for yield stress.

Table 5. Results obtained from ANOVA for yield stress, using adjusted SS for tests.

\begin{tabular}{|c|c|c|c|c|c|}
\hline \multicolumn{6}{|c|}{ Analysis of Variance } \\
\hline Source & $\mathrm{F}$ & Seq SS & Adj SS Adj MS & & $\mathrm{P}$ \\
\hline Combination & 1 & 0,1324 & $0,1324 \quad 0,1324$ & 0,67 & 0,500 \\
\hline Mesh & 2 & 0,3264 & $0,3264 \quad 0,1632$ & 0,82 & 0,549 \\
\hline Error & 2 & 0,3968 & $0,3968 \quad 0,1984$ & & \\
\hline Total & 5 & 0,8556 & & & \\
\hline
\end{tabular}




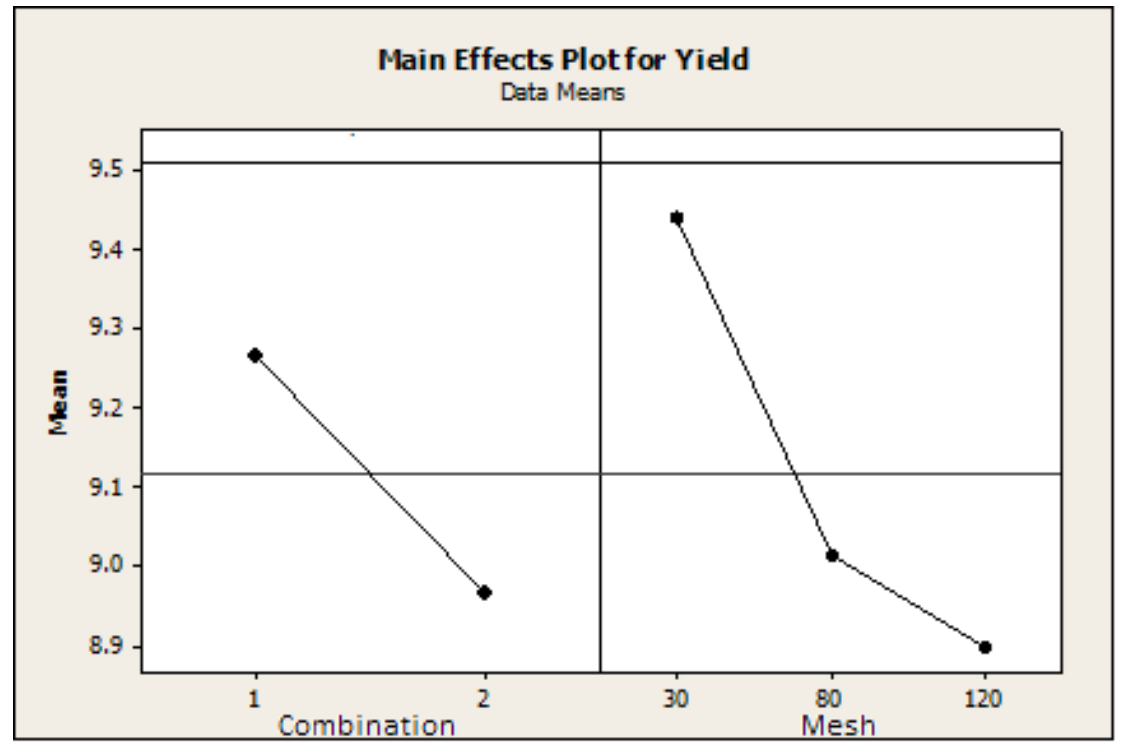

Figure 8. Main effects plot for yield stress.

Yield strain, strain at UTS, and brake point strain follow the same patterns. Increased chile stems particles reduces the strains, which make the material more brittle. Moreover, reduced particle size increase the strains due to a better dispersion through the composite material, which provide better interaction between the particles and the polymer matrices in the presence of MAPP. It is important to notice that the difference between the strains in the 30-mesh grain is lower than in 80 mesh. This is because that 30 mesh grain sizes provide more room for improvement than 80 mesh due to the fact that small grain size gets effectively mixed and better dispersed throughout the matrix than with 80 mesh size grains.

\section{Water absorption results}

Water absorption test was conducted according to ASTM D570-98 standard to study the behavior of the material. Changes in weight after $24 \mathrm{~h}$ immersion in water are listed in Table 6. From Table 6, the combination (A) represent 75\% rPE, 25\% Wood, 30 mesh. Combination (B) represent $75 \% \mathrm{rPE}$, $25 \%$ Wood, 80 mesh. Combination (C) represent 75\% rPE, 25\% Wood, 120 mesh. Combination (D) represent 50\% rPE, 50\% Wood, 30 mesh. Combination (E) represent 50\% rPE, 50\% Wood, 80 mesh. Combination (F) represent 50\% rPE, 50\% Wood, 120 mesh. Combination $(\mathrm{G})$ represent 25\% rPE, 75\% Wood, 30 mesh. Combination (H) represent 25\% rPE, 75\% Wood, 80 mesh. Combination (I) represent $25 \% \mathrm{rPE}, 75 \%$ Wood, 120 mesh.

Water absorption varied between $0,7 \%$ and $4,4 \%$. Further, in Figure 9 a SEM image taken from some specimens under water analysis is showed.

Evidently, reduced particle sizes reduce the water absorption averages due to the lower surface area. In addition, PP content reduce the water absorption, and MAPP lowers water absorption due to a better interaction between fibers and the polymer matrix. However, there are no significant effects from particle sizes on water absorption. 
Table 6. Summary of results obtained for water absorption of WPC.

\begin{tabular}{cc}
\hline Combination & $\begin{array}{c}\text { Water } \\
\text { Absorption } \\
\text { \% }\end{array}$ \\
\hline A & 4,4 \\
\hline B & 1,5 \\
\hline C & 2,0 \\
\hline D & 0,9 \\
\hline E & 0,7 \\
\hline F & 1,1 \\
\hline G & 2,8 \\
\hline H & 0,8 \\
\hline I & 1,9 \\
\hline
\end{tabular}

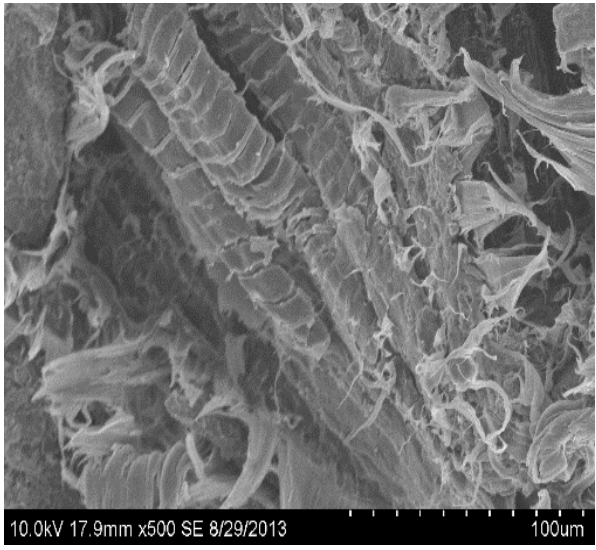

(a)

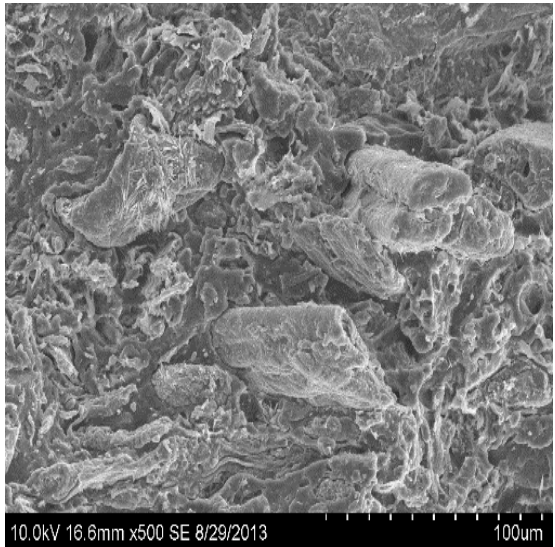

(b)

Figure 9. SEM images of water absorption of WPC (a) 30mesh size, (b) 80mesh size (both samples has the same material compositions).

\section{Morphological Characteristics}

SEM were used to analyze the interaction of the materials with the chile stem particle size at a microscopic scale. Fractured surfaces resulting from the tension test specimens of all material combinations developed by DOE were scanned. From Figure 8 , we can notice that 80 mesh sizes (Figure 10a) mixed better than 30mesh size (Figure 10b). In addition, less voids were observed in samples with $80 \mathrm{mesh}$ than in $30 \mathrm{mesh}$. Moreover, in $80 \mathrm{mesh}$ samples, it is noticeable that the fibers were broken along their axis; meanwhile in the 30 mesh samples, the fibers were pulled out from the matrix. We believe this is due to a better mixing between the matrix and the fibers, along with the presence of the coupling agents, which provided good interaction between the polymer matrix and the fibers. Furthermore, material combinations play a big role in the morphology of the composite material. From Figure 11, we can notice that an increase in the percentage of plastic reduced the voids within the material. Also in this situation, plastic tends to form layers of materials that are clearly distinguishable when we compare the two samples in Figure 11. The fractured surface of the left images (10a and 11a) show that plastic pulled out; meanwhile the right images, with higher percentage of PP brake in layers. 


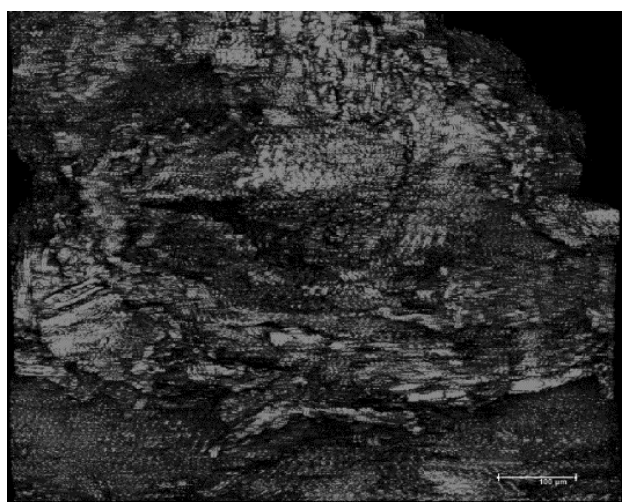

(a)

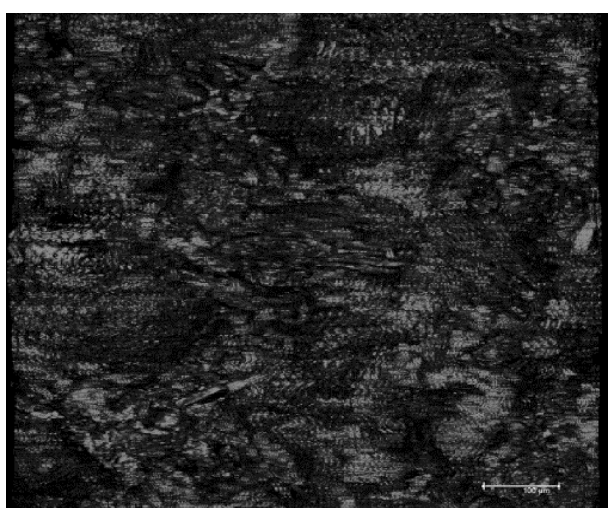

(b)

Figure 10. 3D-Confocal images of WPC produced samples: (a) 30mesh size, (b) 80mesh size.

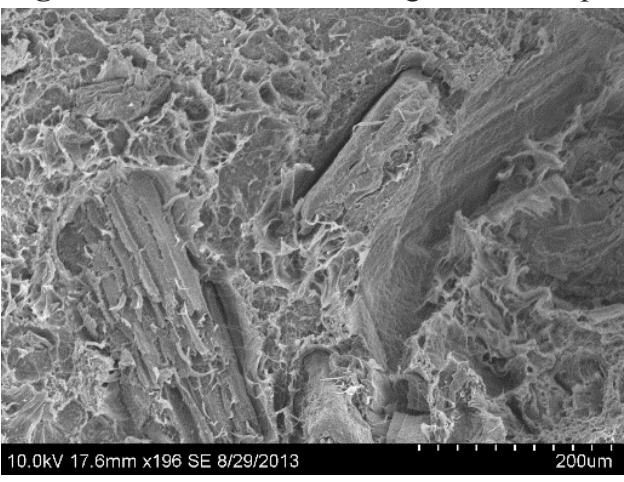

(a)

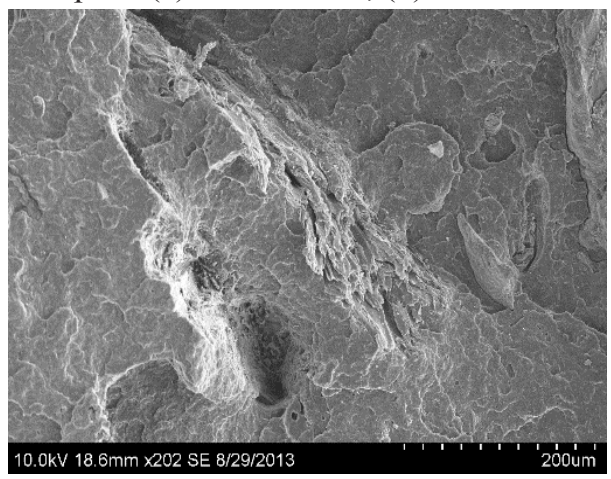

(b)

Figure 11. SEM images of specimens produced. (a) $50 \% \mathrm{PP}$ added to the specimen (b) $75 \%$ of $\mathrm{PP}$ added to the specimen.

\section{DISCUSSION}

In this study Wood-Plastic composites were made using PP and MAPP in combination with chile waste from the New Mexico region. Two different approaches were used to investigate the effects of chile as a WPC.

In the first approach ratios variations between recycled PP and chile were used, and also a variation of mesh size on chili was varied to investigate its mechanical properties. The following discussion are drawn from such work. A decrease in the mesh size of chile stem to 30 mesh will yield the highest levels of ultimate tensile strength with a significance level of 0,08 ; this suggests that as we reduce the mesh size of the chile stems we will increase the UTS levels of the WPC.

Our second approach was implemented using different rations in the combinations of PP, fire retardant, coupling agent, along with chile waste keeping a consistent particle size of 30 mesh. Highest levels of ultimate tensile strength and yield strength were reached by the composite which have both the highest levels of chile at $30 \%$ and coupling agent at $10 \%$. This suggests the structure of the chile added with the couple agent acts as an improvement of the mechanical properties of the wood plastic composites. Incidentally the samples which showed the poorest mechanical properties were those with the highest level of fire retardant at $10 \%$. This suggests that even when fire retardant is a desirable ingredient for obvious reasons; it is in detriment of the integrity of mechanical properties of the final product. In addition, it can be observed that wood fiber length, geometry, and content strongly affect the microcellular structure of the WPC specimens. Due to a finer microcellular structure, the larger grain sizes of wood fiber samples showed higher mechanical properties. One major problem faced is the dispersion of wood particles throughout the matrix. This can be seen in the SEM. Wood particles burned to the sides of the barrel of the injection molding machine due to the light weight of the particles 
and improper mixing (this problem was less prevalent in the 30 mesh wood). In many cases, the melting index of plastic was higher than the degrading temperature for wood. This can cause potential burning and degrading of the wood fiber, which could also limit the mechanical performance of the composite material. The blending of additives in WPC's has been shown to increase proper fiber dispersion, increase outdoor performance, and increase mechanical properties.

\section{CONCLUSIONS}

In this investigation, the effects of material composition and grain sizes on the mechanical and water absorption behavior of a WPC based on chile peppers stalks are analyzed. The results showed that chile stems waste could be used in PP composites as a reinforcing agent. Moreover, it is showed that 80 mesh grain sizes improve the properties better than 30 -mesh size due to a better mixing and smaller surface area as well as lower internal stresses. Material composition also, affect the properties, increasing PP will increase its mechanical properties.

In addition, SEM and confocal images shows that the mixing plays a very important role on the composite properties. More plastic provides more packed material and less voids; also, the coupling agent MAPP showed that using coupling agent fibers make the material brake in the direction of the pulling, whereas, lower coupling agent percentage tends to make the material to be pulled out. This is due to a better interaction between the polymer matrix and chile stem particles.

Future research will focus on including additives to the mix and improving the mixing process of the meld. Red chiles harvesting season comes once a year and lasts a mere 6 months. This gives us a small window to collect chile waste and data from the farms, and analyze the disposal process.

\section{REFERENCES}

Ashori, A. 2008. Wood-plastic composites as promising green-composites for automotive industries. Bioresource Technology 99(11): 4661-4667.

Bouafif, H.; Koubaa, A.; Perre, P. ; Cloutier, A. 2009. Effects of fiber characteristics on the physical and mechanical properties of wood plastic composites. Composites Part A: Applied Science and Manufacturing 40(12):1975-1981.

Fabiyi, J.D.; McDonald, A.G. 2010. Effect wood species on property and weathering performance of wood plastic composites. Composites Part A: Applied Science and Manufacturing 41(10):14341440.

Ozdemir, F.; Ayrilmis, N.; Kaymakci, A.; Kwon, J.H. 2014. Improving dimensional stability of injection molded wood plastic composites using cold and hot water extraction methods. MaderasCiencia y Tecnología 16(3): 365-372.

Pulido-González, H.; Hernandez, E.; Rabelero-Velasco, M.; Sanjuan-Raygoza, R.; JassoGastinel, C. 2014. Mechanothermal performance evaluation of a biodegradable resin as coupling agent for hydrophobic polymer/cellulosic composites. Maderas.Ciencia y Tecnología 16(4): 463-468.

Oh, YS.; Yoo, JY. 2011. Properties of particleboard made from chili pepper stalks. Journal of Tropical Forest Science. 23(4): 473-477

Wang, H.; Chang, R.; Sheng, K.C.; Adle, M.; Qian, X.Q. 2008. Impact response of bambooplastic composites with the properties of bamboo and polyvinylchloride (PVC). Bionic Engineering 5(Suppl): 28-33.

Wechsler, A.; Hiziroglu, S. 2007. Some of the properties of wood-plastic composites. Building and Enviroment 42(7): 2637-2644. 